\title{
Historein
}

Vol 8 (2008)

Performing Emotions: Historical and Anthropological Sites of Affect

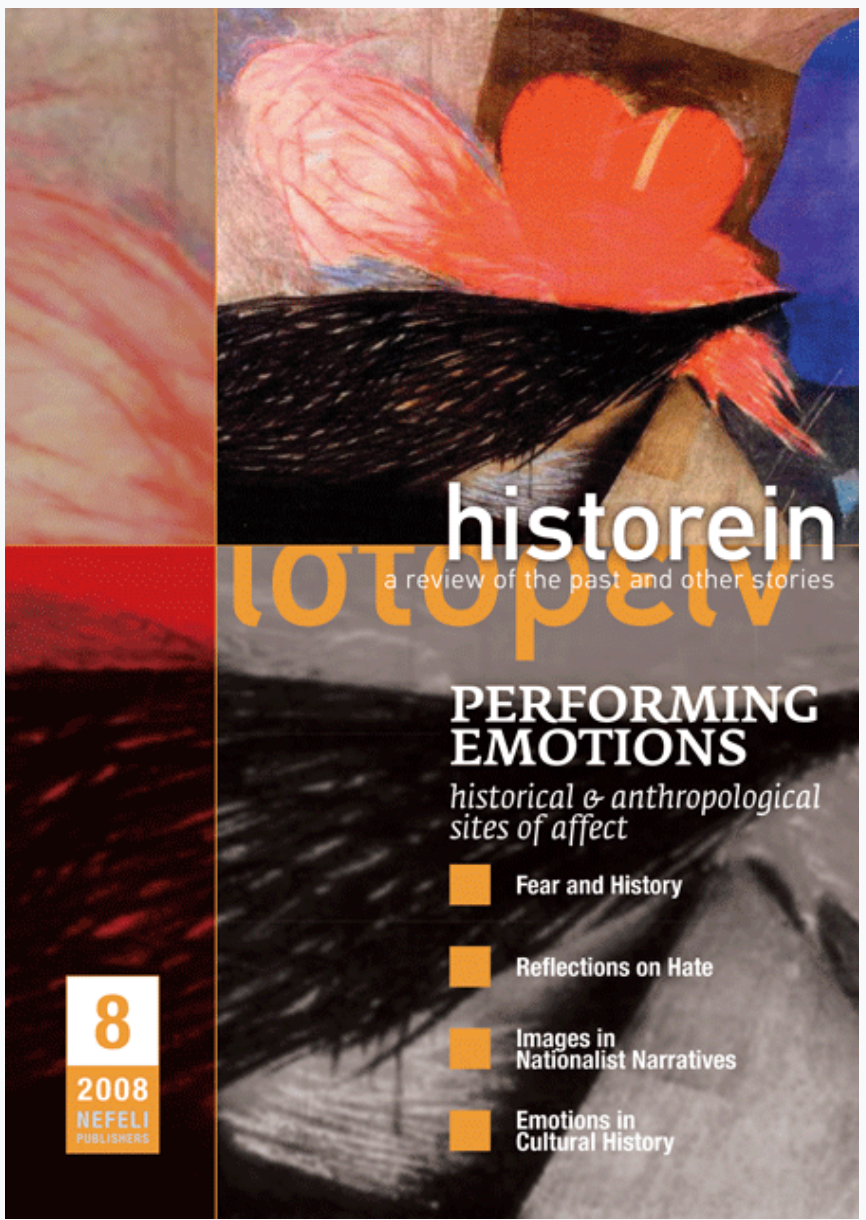

\section{On the Ambiguities of Altruism and the} Domestication of Emotions

Alexandra Bakalaki

doi: $10.12681 /$ historein.40

\section{Copyright (C) 2012, Alexandra Bakalaki}

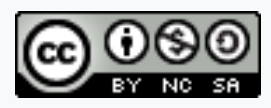

This work is licensed under a Creative Commons Attribution-NonCommercialShareAlike 4.0.

To cite this article:

Bakalaki, A. (2009). On the Ambiguities of Altruism and the Domestication of Emotions. Historein, 8, 83-93. https://doi.org/10.12681/historein.40 
“... we ourselves play 'universe' with our dice." -Roy Wagner, An Anthropology of the Subject

Philanthropic discourses almost invariably emphasise the transformative effects of altruistic giving on both donors and recipients. From this perspective philanthropy is experienced as a context within which subjectivities are constituted rather than as a field wherein already constituted agents pursue set goals. The self is seen as the source of philanthropists' initial motivation for engagement in altruistic service, but also as the subject and the object of transformations brought about by such engagement. Concurrently, the personal constitution and circumstances of the recipients of altruistic help are seen as sources of their material poverty and as targets of reform to be brought about through philanthropic interventions. From the point of view of donors, relations between themselves and recipients are crucial for the prospects of such interventions; hence, they are to be closely monitored. This is especially true of aspects of these relations that are glossed as "emotional" and are construed as implicating the deeper, inner, and ultimately unknowable self.

What follows is an ethnographic account of the practices through which the members of $A / Z,{ }^{\prime}$ a small group of poverty-relief volunteers, realise that emotions constitute both an aspect of the self and a source of power on the self and that the self is potentially both a precious resource and sub-
On the Ambiguities of Altruism and the Domestication of Emotions
Alexandra Bakalaki

Aristotle University of Thessaloniki 
versive enemy. This realisation informs the efforts of $A / Z$ members to educate themselves and the poor they serve to manage their emotions. Ironically, it is precisely through these efforts that they realise that it is in the nature of emotions to escape complete control. Similarly, it is through their efforts to be as authentically altruistic as possible, that that they realise that try as they may, they will always be a little behind.

A/Z was founded in Thessaloniki in 1998 as a relatively autonomous branch of a slightly older association in Athens. Initially, its main mission was to collect leftovers from large receptions given in restaurants and hotels, but also cakes and other delicacies solicited from local bakeries and pastry shops, and to deliver them to orphanages and homes for the elderly and the chronically ill. Implicitly, at least, awareness of the fact that what may be a rare treat for some is expendable surplus to others highlights social arbitrariness and injustice. The practice of recycling leftovers pointed to receptions as sites and metaphors of excessive and provocative consumption, and reinforced the stereotype of elite socialites as idle eaters and drinkers who are indifferent to the suffering of their fellow humans if not downright responsible for a good part of it. ${ }^{2}$

When I first became acquainted with $A / Z$ as a participant observer in the autumn of 2002 , the recycling of leftovers had just been interrupted. Volunteers recalled that it was impractical to wait until receptions had ended and to rush the leftovers to the recipient institutions in the middle of the night before they spoiled. In addition, however, they emphasised that they had eventually realised that helping people improve their circumstances on a more permanent basis is far preferable to charitable gifts of short-lived pleasures. Nowadays, $A / Z$ still supports a municipal soup kitchen and occasionally several institutions with food solicited from local bakeries and pastry shops. However, its main mission is to cater for individual poor households to which it offers food and a mixture of advice, encouragement and disciplinary supervision glossed as "psychological support". To face up to the demands of such support, $A / Z$ solicits the advice of social workers and mental-health professionals.

The background assumptions about the nature of the individual self on which the provision of "psychological support" is based are generated by the support practices that are seen as founded on these assumptions. ${ }^{3}$ As a form of cure, "psychological support" reveals to those who administer it the causes of the ills it aims to treat and it establishes the reasons of its own necessity. Through their personal involvement with $A / Z$ support recipients, ${ }^{4}$ the volunteers discover that the latter's situation amounts to a state of crisis at once financial and (inter)personal. They also discover that to exit this state, they must enter into a process of personal transformation. Finally, volunteers discover that to guide recipients through this effectively, they must develop their own abilities to control their emotions and reactions towards them.

$A / Z$ is coordinated by its two original founders, a male bank employee and painter and a female high-school teacher, both in their forties. Active membership consists of around twenty women and five men, who are mostly middle aged and lower middle class. They include private and public sector employees, pensioners, housewives, and people self-employed in small family businesses. Almost all are practicing Christians. 
The people who contact $A / Z$ seeking help in the form of food for themselves and their families are mostly women, Greek as well as immigrant. They commonly present their problems as the result of a sudden reduction of their household income. This is triggered by circumstances beyond their control such as a rise in rent or some other unforeseeable expense: by sickness, death or divorce; prolonged unemployment; the birth of children or the attachment of older children to the household; the accumulation of debt or the interruption of financial support from relatives. Although volunteers gloss these problems as "crises", thereby implying that they had been unexpected and they are probably resolvable, they are aware that most of the poor who seek $A$ / $Z$ 's support have found themselves in similar circumstances in the past and have received help from their local parish or other charity organisations.

One of $A / Z$ 's basic policies is that, unless applicants are very old or chronically ill, it caters only to people that have come to understand that something is wrong with their lives and have decided to do something about it. As a result, volunteers do not go to the poor; they only consider the cases of those who have taken the initiative to seek help themselves and who seem receptive to the "psychological support" aiming to empower them to improve their situation. Prospective support recipients are visited at home by two volunteers who assess their actual circumstances and inform them that to be eligible for help, they must accept the terms of an informal, notional "contract" stipulating that $A / Z$ will cover their food needs and provide other daily necessities for a limited period of time - usually less than one year - during which they must mobilise themselves to find work and/or have unemployment cards issued, claim state or municipal benefits to which they might be entitled, seek medical, psychological or substance abuse treatment and, above all, try to manage rationally the resources they already have, however limited they might be. At the end of the agreed period, the "contract" may be renewed if they still need help, provided that recipients can prove that they have done all they could to find solutions to their problems.

Successful applicants are put under the charge of a specific volunteer whose basic duty is to visit their household weekly or biweekly with or without notice. During these visits $\mathrm{s} /$ he brings food and other material goods, and also offers updates on job openings, social benefits and free services for the poor, advice and suggestions on money earning or saving strategies, and encouragement. However, the volunteers' most challenging duty is to supervise support recipients, by checking whether they are indeed meeting their obligation to improve their self-reliance and that they are not just using $A / Z$ as a temporary source of free food. Although volunteers emphasise the need for mutual trust between themselves and the recipients in their charge, whenever possible, they cross-check the accounts of the latter even if this means violating their privacy or obtaining privileged personal information. For example, they always contact the employer for whom a person they support claims s/he has started to work, or the medical doctors or psychologists whose help $\mathrm{s} /$ he claims to have sought.

Collecting, storing, and transferring food to the recipients' homes is time consuming and arduous. Volunteers consider these tasks secondary to the more challenging demands of "psychological support", and the necessary balancing between the role of a friendly visitor too polite to interfere with his/her host's affairs and that of an unwelcome intruder. In many ways, volunteers see themselves as educators and they struggle to be accepted as such. Deeply committed 
to the cliché according to which providing the hungry with free fish means that they will never learn how to fish on their own, they try to teach recipients skills that will enable them to become self-sufficient. However, they know that for the teaching to be successful, recipients have to be willing to learn, and this may require some coercion. Appropriately, the phrase they use to summarise the policy of home visits, namely "food is a tool with which we open closed doors" has connotations of both rescue operations and of forced entries. ${ }^{5}$

For recipients, $A / Z$ is a rather abstract entity; they only come in contact with the specific volunteer to whom they have been assigned. The volunteers, who pay their visits at their own discretion and without ever disclosing their phone number and address, nevertheless refer to recipients in their charge as "my family(ies)". They also liken $A / Z$ to a family that is similar to the families it serves in that it is poor too. Unlike them, however, it is poor by choice: it does not engage in fundraising and it has minimal expenses because its members put priority on influencing the poor through personal involvement instead of impersonal material donations. They also think that giving money to the poor may be more dangerous than giving fish to the hungry, because, unlike fish, money may be used to sustain bad habits. Finally, volunteers also liken $A / Z$ to a healthy, functional organism. Though remaining stable, if not declining in size, it is maturing as its members become more skilled in their support techniques and more sophisticated in their appreciation of the conditions which make this support necessary.

Indeed, $A / Z$ volunteers are becoming increasingly firmer in their conviction that the material poverty of those who seek their support is a symptom of psychological passivity or resignation which, in turn, they attribute to deeper, complex, pernicious and often well-concealed causes. These include dependence on substances, but also on the care, but sometimes also the abuse by others, immaturity, irresponsibility, lack of self-respect and self-confidence, and a tendency to manipulate others. Although volunteers recognise these as personal faults, they also interpret them as indexes of psychological traumas, which, in turn point to 'dysfunctional' families and social environments.

Recipients are thus blamed and exonerated at the same time: they are responsible for their troubles, but these troubles are "psychological", and as such, they are beyond their conscious control. For the volunteers this means that there is no point in getting angry or impatient with support recipients unable or unwilling to co-operate. Moreover, volunteers admit that if they were in the recipients' position, they would probably feel and do worse. In doing so, they emphasise the importance of personal initiatives in overcoming poverty, while accepting, at the same time, that controlling one's emotions is very difficult.

The self-perpetuating assumption that what happens inside the self/mind/soul is more important than visible material poverty is both the starting point of the volunteers' support strategies and the prism through which they assess their relative effectiveness. For example, a volunteer interpreted the fact that a young mother who had been out of work for a long time accepted the job the volunteer had found for her as the result of an "internal change" brought about by the "psychological support" she had received. She explained that the woman had finally come to accept that her husband had deserted her for good, was not going to take pity on her and return to 
care for her and the children no matter how poor she stayed. Similarly, when a very poor couple with six children spent a relative's monetary gift to buy an expensive television set, which - incidentally - was too big for the tiny living room and would harm the children's eyes, volunteers agreed that their behaviour was immature and irresponsible: the couple's refusal or failure to change "inside" would make their family even poorer.

Since 2002, A/Z's coordinators have invited social workers, special issue councillors, psychologists and psychiatrists to speak to the group and lead discussion groups. In addition, in 2004 they made an exception to their commitment to keep $A / Z$ expenses to a minimum and hired a parttime social worker who meets with smaller groups of five volunteers once a month. The priority volunteers put on "psychological support" is both the cause and the outcome of their regular contacts with these experts.

In many respects, the relationship between volunteers and experts is similar to that which volunteers try to cultivate with recipients. Not only do the volunteers not challenge the authority of the educated professionals, but they underline it by admitting that at least sometimes they find the experts' advice hard to follow, because it is "too advanced". For example, volunteers confess that although they know that their relationship with recipients should be based on mutual trust and that they should view them as whole persons of equal worth to themselves, they often catch themselves feeling condescending pity, anger, suspiciousness or just self-congratulating pleasure at their own superiority. On other occasions, they laugh at themselves for getting overzealous in their therapeutic tasks, or for realising that they had misunderstood the experts' advice and done the wrong thing. Finally, sometimes they pose embarrassing questions. For example, on hearing the social worker expound on the importance of listening carefully to support recipients' needs and expectations, a volunteer wondered, "They come here because they need the food, but we make them go through the contract, the home visits and all the rest and they go along because they have no choice. If we ask them what they want and they tell us clearly and explicitly that they want only food, what are we to do?" Answering her own question, she suggested that one is better off not asking questions one cannot handle.

According to the experts, the most important issue volunteers face concerns the need to define and protect the appropriate boundaries between themselves and the people they support and to ensure the latter do likewise in relation to others, including family members and close relatives. Despite or rather because of this emphasis, the volunteers discover that maintaining the boundaries of the self is no easy task. Without ever challenging the authority of the experts, they occasionally complain that their advice "feels wrong" or even worse, puts them into a double bind. Here are some examples: The volunteers often discover that the people they support channel some or even all of the food they receive from $A / Z$ to third parties. In such cases they must demand to be brought into direct contact with the secret food recipients or else the food gifts stop immediately. This policy is based on the understanding that such incidents are symptoms of the recipients' lack of personal autonomy, of their inability to stand up to intimidating others or of their need to keep others dependent on themselves. However, sometimes at least, volunteers realise that preventing or penalising secret food handouts goes against their duty to respect the choices of the people they support. Challenging long-standing cultural values concerning intra-family solidarity 
or maternal sacrifice makes volunteers especially uncomfortable. Thus, when the social worker urged a volunteer to stop the delivery of food to the relatives of a rightful $A / Z$ recipient, she objected: "they [the recipients of the secret handouts] are family, how can I say 'you shall not share'?" Another commented on an old woman who spends her small pension and a good part of the food she receives on a spendthrift son: "It is obvious that he is exploiting her, but I feel for her, because I am a mother too: he demands, she gives - what else can she do?"

Sometimes the volunteers admit that their feelings make it impossible to keep a distance from the people they support and to see their situation objectively. One concluded her progress report on an uncooperative recipient with the following words: "I am afraid I cannot do much more; she is an adult, and she is doing nothing to meet our $[\mathrm{A} / \mathrm{Z} \mathrm{s}]$ terms. It seems that this is her choice and so what I should do is explain that we cannot go on supporting her. But I keep saying, give her a little more time ... I feel sorry for her."

The experts never tire of reminding volunteers that they should never take responsibility for the problems of recipients as this may encourage the latter's irresponsibility or resignation. They should also keep their compassionate feelings in check and make sure they do not put themselves in the recipients' shoes lest they too become pessimist, fatalistic or discouraged.

The prospect of terminating the support of households with small children or other dependents is a sensitive issue because, apart from compassion, it evokes feelings of guilt. Given that most households fall into this category, $A / Z$ hardly ever abandons people who have failed to meet their "contract" unless they have access to some other source of support like the parish, another charity organisation, or relatives. Thus, almost a year after the purchase of the oversized TV set, the parents of the six children continue to receive food from $A / Z$. However, on the occasions when $A / Z$ withdraws its support, experts advise volunteers to keep in mind that this is a predicament that recipients have brought onto themselves - ultimately it has been their choice not to honour their "contract" with $A / Z$.

The volunteers seem to welcome the experts' advice because it is exonerating, but perhaps also because it gives them an opportunity to emphasise that, although they think it is correct, it is difficult for them to follow it because it goes against their compassionate feelings. They often admit that, although they find establishing a "contract" with recipients necessary, they hesitate to use the term because it sounds "too cold". And as for the experts' advice, in the words of one volunteer, "it speaks to the mind more than to the heart". Finally, on the not so rare occasions when volunteers admit to having violated the policy against giving personal gifts to recipients, they admit that they could not help it; they knew it was against the rules, but it felt right emotionally. Again, the words of a volunteer are illustrative: "It was the human being in me that took charge ... what can we do, we are not automata..."

On such occasions the experts explain that the objective is not to eliminate emotions altogether, but to learn to control them. They remind volunteers that overly positive emotions towards recipients may cloud their vision and inhibit rational sound judgment as much as negative ones. Volunteers must always try to be objective and also to watch for any mischief, lies, flattery, emo- 
tional blackmail or guilt-tripping the poor may try to pull on them. The experts also warn volunteers that the more they identify with recipients, the less emotional protection they will have against the devious and manipulative strategies recipients sometimes use to hide secret income or to mislead volunteers about the ways they spend their money or the reasons why they keep losing jobs. Despite these warnings, volunteers find it hard not to take such behaviour personally; "after all, they say, it is only human to feel hurt when you try to do your best to help someone and you realise that to them you are nothing but a resource to exploit." Such feelings of hurt trigger new explanations by the experts, and the circle keeps repeating itself.

The relationship between experts and volunteers reinforces the very need which it appears to fulfil. The more the volunteers try to match the experts' advice, the more they realise that they are lagging behind. Needless to say, support recipients are still further behind, as, after all, most of them just put up with the volunteers' supervision because they need the food that comes along. In contrast, the volunteers cherish their implication in "psychological support" and they view their apprenticeship to the experts as part of a "long journey of self-discovery", "a personal trajectory" or "an opportunity to work on themselves". They often comment on how applying the skills and techniques of psychological support to their private lives - for example, holding their ground against the demands on others or not being overprotective - has improved their relations with others, and especially with their teenage or young adult children.

Perhaps the most important lesson that the volunteers both learn and teach is that the most valuable asset and the hardest obstacle in the struggle for survival is oneself. ${ }^{6}$ Considering this condition as embedded in human nature, they see both themselves and those they support as subject to it, and therefore similar in this respect. At the same time, however, volunteers feel that they differ from recipients because the latter neither comprehend nor accept this predicament. The implication is, of course, that if they did, they would not be poor. However, the volunteers acknowledge that the attitude of recipients is not all that unusual. After all, the majority of the general population believes that "society" is a real entity that exists above and beyond the individuals that comprise it and, even worse, that it can be held responsible for their welfare. Although the volunteers agree that in the final analysis the causes of poverty are economic and political, and are quite concerned about the increasing rates of poverty nationally and internationally, they emphasise that both the victims of poverty and those who come to their aid are concrete individuals. Relegating responsibility for the poor to "society", they say, legitimates personal irresponsibility. They also criticise public services for the poor because they are subjected to vote-hunting priorities, bureaucratic efficiency and often involve lazy or uncaring practices. These views are hardly surprising given the widespread and ethnographically well-documented tendency among Greeks to blame the state for failure in its role as a pastoral or parental figure. ${ }^{7}$ However, it is perhaps worth emphasising that by criticising bureaucrats for fishing for votes and caring for measurable outcomes rather than for suffering persons, volunteers imply that, inefficiency aside, the state is unsuitable to delve into personal problems which require personal attention of the sort that volunteers can provide.

More generally, in the context of $A / Z$ s v vocabulary, the connotations of "society" and related terms are usually negative. For example, referring to fundraising fashion shows, dances or other "so- 
cial event" gatherings, volunteers implicitly question the authenticity of the "party-going philanthropists" that organise and attend them. It is also perhaps significant that the word "social" hardly ever specifies "solutions", but usually refers to "problems" like drug addiction, consumerism, the idealisation of fast and easy wealth or the erosion of family values. Above all, however, volunteers are weary of the notion that "society" is an entity endowed with agency and obligations, and they systematically try to disabuse recipients of any tendency to put either hope or blame on "society". They drive the point home by reminding them systematically that $A / Z$ does not represent "society", but it is a bunch of concerned individuals who do not owe anybody anything but which has taken voluntarism by choice.

\section{Emotion as a basis, means, and metaphor for altruism}

Concepts such as "philanthropy", "charity" or altruism" are not coherent or stable over time and the meanings, values and practices they refer to cannot be neatly classified into clear categories. $A / Z$ members themselves are aware that philanthropy and volunteerism mean different things to different people and take pride in the policies that distinguish their group from others, both secular and Christian. However, although they consider their own approach to poverty relief more open-minded, innovative and "scientific" than that of "classic" or "traditional" philanthropists, they assume that the problems and dilemmas they face are shared by others with whose practices they may disagree. Indeed, despite the differences in their approach to poverty relief, philanthropists are almost invariably preoccupied with issues concerning the similarities and differences between themselves and the poor, as well as with the ways in which the deserving poor may be distinguished from the undeserving ones and authentic altruism may be distinguished from self-aggrandisement. They are also preoccupied with problems concerning the balance between emotion and reason, between empowering encouragement and disciplinary control, and between the sense of duty to relieve burdens and the need to ensure that such relief will not encourage idleness. ${ }^{8}$

However, what is perhaps distinctive about $A / Z$ is that its members attach great value to facing up to the challenges involved in establishing a close personal relationship with the poor, but at the same time they also worry a lot about keeping their distance from them. I suggest that far from being mutually exclusive, the prospects of achieving closeness and maintaining distance are part of a dynamic whereby each enables the other and is reinforced by it. If, after Geertz, one were to take this dynamic as the basic plot of a story volunteers tell themselves about themselves and the world, the moral of the story would be that unselfish solidarity with those worse off than oneself is extremely difficult. In the context of the neoliberal ontology which Margaret Thatcher aptly summarised with the diction "in reality society does not exist", things could hardly be otherwise: uninterested solidarity with others is not in the natural order of things, but takes great effort to build and to feel, because people have themselves to look after first..$^{10}$ On the other hand, however, individuality is a prerequisite for compassionate or altruistic relations with others. In other words, individuality is both an obstacle and asset for helping others. Indeed, it is hardly surprising that altruistic claims are interpreted as signs of noble and sometimes naïve character, but they are also suspected of being hypocritical. 
However, from the perspective of the practices I have tried to describe, the notion of individuality is itself destabilised to the extent that, for volunteers, emotion - what and how one feels - simultaneously is part of one's self identity and the object as well as the driving force of an exploration undertaken by the self in order to change the self. If emotion is part of the effort by which it is discovered, "1 the effort of the volunteers to get to it renews the causes which make the effort necessary. Their emphasis on the need to manage emotions through "contracts" and to maintain the boundaries of the self reinforces the impression that volunteers have a surplus of compassion, which they should manage rationally for their own sake as much as for the sake of recipients. However, the very effort to control emotions reinforces the sense that they escape complete domestication. ${ }^{12}$ After all, in our part of the world, "authentic" emotions are distinguished exactly by their resistance to being fully accessed or controlled by reason. Thus it is expected that, while personal feelings largely determine one's objects and procedures of knowledge, they never become fully known - objectified, measured or interpreted. In this respect emotions are as volatile and vulnerable as gifts which cease to be "real" once acknowledged as such. ${ }^{13}$

Recalling Catherine Lutz's insight that in the Western world emotion and ambiguity are synonymous, ${ }^{14}$ I would suggest by way of conclusion that, apart from its instrumental value as means of disciplinary control, the belief that helping people out of poverty is a matter of conquering emotions is a reminder that unselfish giving is perhaps ultimately impossible. Students of philanthropy have pointed out that "philanthropy" resists definition. Its meanings, values and strategies are multiple and flexible. The long-lasting power of the ideal of philanthropic altruism has been attributed to the fact that this ideal speaks to different people in different ways and tells them many and variable things. ${ }^{15}$ Perhaps one of the things it says is that whatever it says can never be enough. In other words, the philanthropic rhetoric is powerful because, and not despite of, the fact that it provides a perspective from which the ambiguities of altruistic giving become visible and intelligible. In other words, it renders the struggle with these ambiguities meaningful, necessary and, ultimately, heroic.

\section{NOTES}

Acnowledgements: Many thanks to Athena Athanasiou, Rika Benveniste, Eleni Goni, Venetia Kantsa, Efi Voutira and Samis Taboh for reading and commenting on earlier drafts, and especially to Costas Douzinas for our conversations on related issues and for his help in editing the final draft.

1 The name is made up.

2 Eating is a metaphor for selfish, aggressive consumption and theft in many cultures. For its uses and meanings in Greece, see Michael Herzfeld, The Poetics of Manhood. Contest and Identity in a Cretan Mountain Village, Cambridge: Cambridge UP, 1985; Michael Herzfeld, Anthropology through the Looking Glass. Critical Ethnography in the Margins of Europe, Cambridge: Cambridge UP, 1987; Giannis Kiourt-

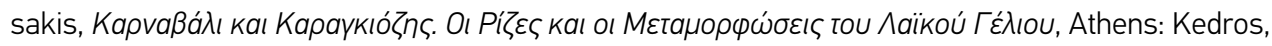
1985, pp. 321-340. 
3 The idea that unbeknown to actors, their habitual actions constitute the "reality" in the context of which these very actions and the practices, agencies and relations through which they come about are intelligible, is the point of departure of Pierre Bourdieu (see, for example, Outline of a Theory of Practice, Cambridge: Cambridge UP, 1977; The Logic of Practice, Stanford, CA: Stanford UP, 1990), Marilyn Strathern (see, for example, The Gender of the Gift, Berkeley, CA: University of California Press, 1988; After Nature: English Kinship in the Late Twentieth Century, Cambridge: Cambridge UP, 1992) and Roy Wagner (The Invention of Culture, Englewood Cliffs, NJ: Prentice-Hall, 1977; An Anthropology of the Subject. Holographic Worldview in New Guinea and its Meaning and Significance for the World on Anthropology, Berkeley, CA: University of California Press, 2001). After these theorists, I assume that people's experiences and interpretations of the social conditions of their existence are themselves shaped by these conditions, which, in turn, are the emergent outcome of human action rather than its taken-for-granted environment. On the basis of this assumption, I prefer to refer to the process through which volunteers arrive at notions concerning the constitution of human nature and society as discovery rather than as social construction. On this issue, see also James F. Weiner, Tree Leaf Talk. A Heideggerian Anthropology, Oxford and New York: Berg, 2001, pp. 161-173.

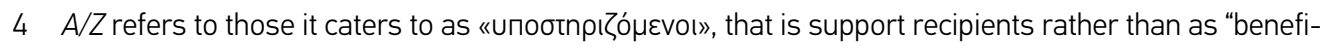

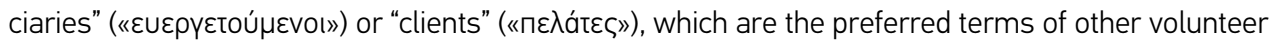
support groups.

5 Although $A / Z$ members consider home visits a modern strategy that distinguishes their approach to poverty relief from others more "classical", "traditional", or conventional", this strategy seems to be as

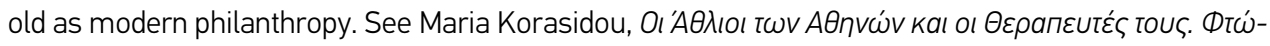

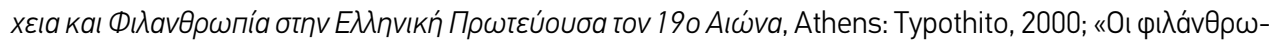

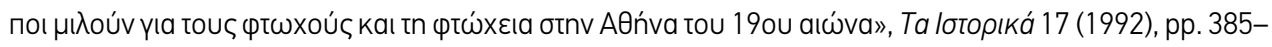
404; Mary Poovey, Making a Social Body. British Cultural Formation, 1830-1864, Chicago and London: University of Chicago Press, 1995. Katerina Rozakou observes that the volunteers she has studied also attach great value to becoming admitted to the living quarters of the refugees they serve. See Katerina

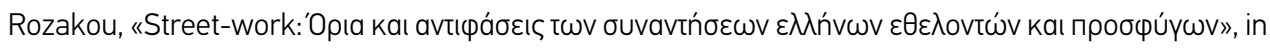

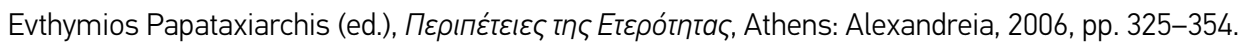

6 On the pressures to render oneself manageable and predictable because it is the only resource which one may exercise control over and rely on in the context of late capitalism, see Christopher Lash, The Minimal Self. Psychic Survival in Troubled Times, New York: Basic Books, 1984.

7 On representations of bureaucracy and bureaucrats as impersonal, indifferent and ultimately inhuman, see Michael Herzfeld, Social Production of Indifference. Exploring the Symbolic Roots of Western Bureaucracy, University of Chicago Press, 1993; on representations of the state as a paternal figure in Greece, see idem, "The Etymology of Excuses. Aspects of Rhetorical Performance in Greece", American Ethnologist 9:4 (1982), pp. 644-663; Idem, Cultural Intimacy. Social Poetics in the Nation State, New York and London: Routledge, 1997.

8 Without suggesting that their weight and meanings are the same in different contexts, I am impressed by the regularity with which these issues surface in different times and places both among philanthropists, volunteers and NGO members themselves, but also among those supportive or critical of their practices. Documenting the point thoroughly is impossible here, but for evidence supporting the argument that such dilemmas have been at the core of modern philanthropic practices since their inception, see Alexis 
de Tocqueville's Memoire sur le Pauperismes, which was first published in 1835 (Alexis de Tocqueville, Mvnuóvı yıa in Фićxeıa, transl. Eliza Papadaki, Athens: Polis, 2005). For anthropological perspectives that might be relevant to interpreting the centrality of these dilemmas, see Ilana Silber, "Modern Philanthropy. Reassessing the Validity of a Maussian Perspective", in Wendy James and N. J. Allen (eds), Marcel Mauss. A Centenary Tribute, New York: Berghahn, 1998, pp. 134-150; Thomas Widlock, "Sharing by Default? Outline of an Anthropology of Virtue", Anthropological Theory 4:1 (2004), pp. 53-70.

9 See Clifford Geertz, “Deep Play: Notes on the Balinese Cockfight”, in idem, The Interpretation of Cultures, New York: Basic Books, 1973, pp. 412-454.

10 See Marylin Strathern, "The Concept of Society is Theoretically Obsolete: For the Motion (I)", in Tim Ingold (ed.), Key Debates in Anthropology, London and New York: Routledge, 1996, pp. 60-66; idem, After Nature; On the historical roots of the native anthropology of Western society whereby human beings are inherently faulty and divided and on the hold of this assumption on social theory, see Marshall Sahlins, "The Sadness of Sweetness", Current Anthropology 37:3 (1996), pp. 395-415.

11 In the words of Roy Wagner, "We have no emotions that are not part of the process of figuring out what they themselves might be ..." (Wagner, An Anthropology of the Subject, p. 252).

12 See chapters 3 and 8 of Catherine Lutz, Unnatural Emotions: Everyday Sentiments on a Micronesian Atoll and their Challenge to Western Theory, Chicago: University of Chicago Press, 1988.

13 Lutz, Unnatural Emotions. On the impossibility of the gift from the perspective of Western sensibility, see Jacques Derrida, Given Time: I. Counterfeit Money, transl. Peggy Kamuff, Chicago and London: University of Chicago Press, 1992. On the idealisation of the uninterested gift from the perspective of Western sensibility, see Jonathan Parry, "The Gift, the Indian Gift and the 'Indian Gift", Man 21:3 (1986), pp. 453-473.

14 The debate among anthropologists over whether emotions are biologically based, socially constructed or both is perhaps itself a manifestation of the ambiguity Lutz describes. On the issues of the debate see Catherine Lutz and G. M. White, "The Anthropology of Emotions", Annual Review of Anthropology 15 (1986), pp. 405-436. For a recent concise summary of the debate, see Maruska Svasek, "Introduction: Emotions in Anthropology", in Kay Milton and Maruska Svasek (eds), Mixed Emotions. Anthropological Studies of Feeling, Oxford: Berg, 2005, pp. 1-24. For a more general commentary on emotions from the perspective of social theory, see Simon J. Williams, Emotion and Social Theory, London: Sage, 2001.

15 See, for example, Alan Kidd, "Civil Society or the State? Recent Approaches to the History of Voluntary Welfare", Journal of Historical Sociology 15:3 (2002), pp. 328-342; Donileen R. Loseke, "'The Whole Spirit of Modern Philanthropy': The Construction of the Idea of Charity, 1912-1992", Social Problems 44 (1997), pp. 425-444. 